\title{
Glass Frit as a Hermetic Joining Layer in Laser Based Joining of Miniature Devices
}

\author{
Qiang wu \\ Technological University Dublin, qiang.wu@tudublin.ie \\ Norbert Lorenz \\ Heriot-Watt University \\ Kevin Cannon \\ Heriot-Watt University
}

See next page for additional authors

Follow this and additional works at: https://arrow.tudublin.ie/engscheceart

\section{Recommended Citation}

Wu, Q. et al. (2010) Glass Frit as a Hermetic Joining Layer in Laser Based Joining of Miniature Devices, IEEE Transactions on Components and Packaging Technologies, vol. 33, no. 2, pp. 470-477. doi:10.1109/ TCAPT.2010.2045000

This Article is brought to you for free and open access by the School of Electrical and Electronic Engineering at ARROW@TU Dublin. It has been accepted for inclusion in Articles by an authorized administrator of ARROW@TU Dublin. For more information, please contact arrow.admin@tudublin.ie, aisling.coyne@tudublin.ie, gerard.connolly@tudublin.ie.

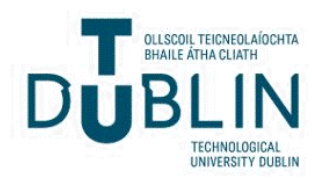


Authors

Qiang wu, Norbert Lorenz, Kevin Cannon, and Duncan Hand

This article is available at ARROW@TU Dublin: https://arrow.tudublin.ie/engscheceart/162 


\title{
Glass frit as a hermetic joining layer in laser based joining of miniature devices
}

\author{
Qiang $\mathrm{Wu}^{1,2}$, Norbert Lorenz ${ }^{1}$, Kevin Cannon $^{3}$ and Duncan P. Hand ${ }^{1}$ \\ ${ }^{1}$ Applied Optics and Photonics Group, School of Engineering and Physical Sciences, Heriot-Watt University \\ EH14 4AS UK \\ ${ }^{2}$ currently with Photonics Research Centre, School of Electronic and Communications Engineering, Dublin Institute \\ of Technology, Kevin Street, Dublin 8, Ireland \\ ${ }^{3}$ GE Aviation Systems, Alexandra Way, Ashchurch, Tewkesbury, Glos GL20 8TB
}

\begin{abstract}
In this paper we investigate the feasibility of using a laser as the heat source to drive a hermetic joining process based on a glass frit intermediate layer. The laser allows the necessary heat energy to be provided in a localised manner; important either as part of a multi-stage process, or to allow thermally-sensitive materials to be used inside the package. Our study includes an investigation of the impact of rough and grooved surfaces on the hermeticity and strength of the join, demonstrating the robust nature of the process, and its ability to allow feed-throughs to the centre of package. Hermetic sealing is demonstrated, with leak rates of $10^{-9}$ mbar $1 \mathrm{~s}^{-1}$, satisfying the military standard MIL-STD-883G.
\end{abstract}

Keywords: Laser joining, glass frit

\section{Introduction}

Many miniature optical, electronic and micro-mechanical systems, for example MEMS (Micro-Electro-Mechanical Systems) require hermetic sealing with long-term stability. The dictionary definition of the term hermetic is a seal that is completely gas tight or impermeable to gas flow. With MEMS technologies it means an air tight seal which will keep gases and moisture out of the package; hence failure of the device due to condensing water vapour inside the package is avoided. Appropriate bonding processes can ensure that a package remains dry and at a high vacuum for years. As no seal is perfect standards have been defined to describe the conditions and leak rates under which seals are still considered to be hermetic. These include the MIL-STD-883G Method 1014.11, JEDEC Standard JESD22-A109-A and ASTM F134-85, all of which are variants of each other. A description of the leak tests according to these standards is given in [1]. 
A number of different hermetic joining techniques have been developed for miniature devices, typically requiring the whole device to be heated to a high temperature. However, this whole package heating limits the ubiquity of the process, (i) causing problems in manufacturing processes where a number of thermal process steps are carried out in sequence, when a later heating step can cause parts joined earlier to disassemble; and (ii) preventing the use of temperature-sensitive materials inside the device e.g. polymers or magnetic materials. Alternative, more localised, techniques have therefore been developed, including resistive heating [2-5]; microwave heating [6]; and induction heating [7-8]. These require specialised modified components and/or materials; our approach is to instead use a laser to provide this localised heating. Lasers are, of course, widely used in a range of joining processes, including the joining of dissimilar materials such as cemented carbides to steel [9], magnesium and aluminium [10], and borosilicate glass to fused silica [11]. These techniques create a direct bond without any intermediate layer; however they normally require both a high temperature and highly cleaned polished contact surfaces. The use of an intermediate layer has advantages which include a relatively low joining temperature (few hundred degrees Celcius), and less stringent requirements for contact surface smoothness. Suitable intermediate layers include Au/Sn solder [12], Zn [13], Al, Au [14], In [15], Ti [16], thermosetting polymer benzocyclobutene (BCB) [17], or glass frit [18-22]. Glass frits are of particular interest due to the required low bonding temperatures ( $<595 \mathrm{~K}$ ), their ability to deliver a hermetic seal with moderately rough bonding surfaces, and to conform to the surfaces being bonded - even to the extent of allowing metallic feed-throughs to be included in the joining layer [19-20]. However current glass frit-based technologies are based on whole-package heating in a furnace. Laser based joining should allow the advantages of glass frits to be applied to temperature-sensitive processes and/or materials, and in multi-step manufacturing processes; however to our knowledge there has to date been no report on laser-based joining using a glass frit intermediate layer.

Frit is simply broken particles of glass, sorted by various grind sizes, and held in a suitable binder, typically as a paste. Sizes range from finely ground powder to small chunks. The glass frit used in our experiments is DM2700P/H848 from DIEMAT [23]. The paste comprises a low temperature glass powder loaded in an organic system which must be burnt out completely, and the glass glazed, before joining. It can be screen-printed, stencil-printed or dispensed (e.g. from a syringe) onto one of the surfaces to be joined; in our experiments a syringe was used to provide a layer of about $250 \mu \mathrm{m}$ thickness once glazed. The part with deposited glass frit paste is then heated to $520 \mathrm{~K}$ for 30 minutes to provide the organic burn-out before glazing for 1 minute at $620 \mathrm{~K}$. The glazed surface is then mated to the other 
component under slight pressure and fired at a peak temperature ranging from 593 to $648 \mathrm{~K}$ for as little as 1 minute to achieve a reliable, hermetic seal.

In this paper we investigate the feasibility of this glass frit / laser process with 4 different miniature packages:

(i) LCC (Leadless chip carrier) package. This consists of an alumina-based substrate containing a recess, to which a $\operatorname{Kovar}^{\mathrm{TM}}$ lid is bonded;

(ii) planar LTCC (low temperature co-fired ceramic), an alumina-based ceramic to which a Kovar ${ }^{\mathrm{TM}}$ “top-hat” lid is bonded;

(iii) planar AlN (Aluminium Nitride) to which a Kovar ${ }^{\mathrm{TM}}$ “top-hat” lid is bonded;

(iv) planar silicon substrate to which either a $\operatorname{Kovar}^{\mathrm{TM}}$ or Nickel cap is bonded.

All are realistic packages used in actual device manufacture.

We first of all concentrate on the ability of the laser to provide the required localised heating, but without taking measures to prevent heating inside the devices due to lateral conduction. We subsequently investigate the ability of the laser/glass frit process to bond rough and grooved surfaces, and finally describe a process whereby the temperature inside the device is minimised by the use of appropriate heat-sinking, including both experimental and simulation results.

\section{The laser-glass frit joining process}

The laser used is a fibre-delivered diode array operating at $940 \mathrm{~nm}$ (Laserline, fibre core diameter $200 \mu \mathrm{m}, \mathrm{NA}=0.22$ ). A galvanometer scanner was used together with an f-theta lens to provide a focused spot of diameter 1 mm which could be moved at high speed across the workpiece. Alternatively, an axicon lens could be used together with a conventional lens to generate a ring focus, as described in section 4.3 below. A schematic of the laser bonding arrangement is shown in Figure 1(b). 


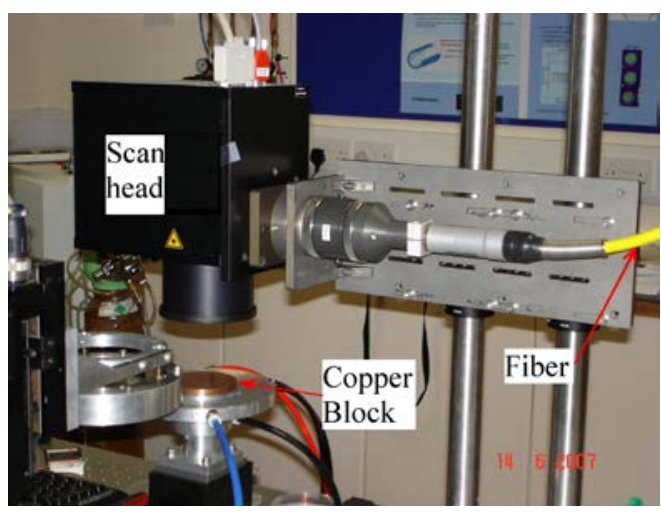

(a)

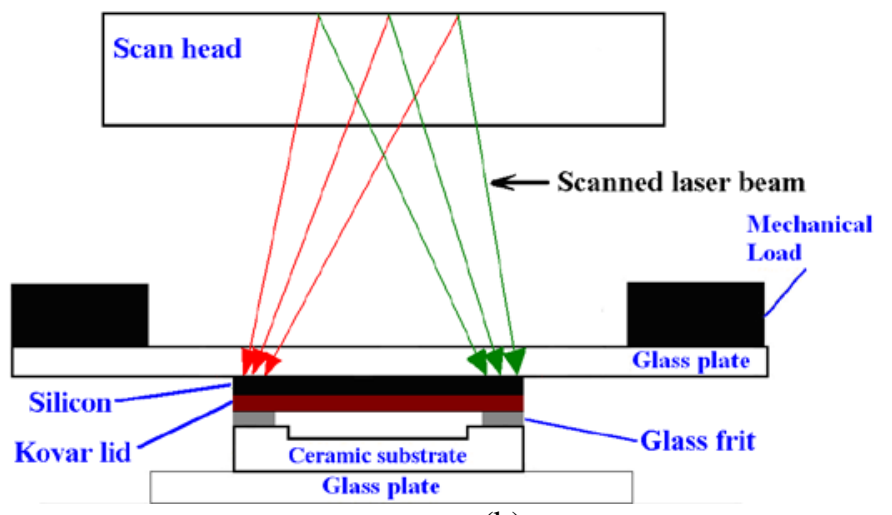

(b)

Figure 1 (a) experimental setup and (b) schematic of laser bonding with scanned laser beam

\subsection{Laser bonding of LCC (Leadless Chip Carrier) packages}

The LCC substrate is made from a high temperature co-fired ceramic, made by companies such as Kyocera and NTK. The ceramic is mostly (90\%) alumina $\left(\mathrm{Al}_{2} \mathrm{O}_{3}\right)$, with some other glassy materials for binding. The dimensions of the Kovar $^{\mathrm{TM}}$ lid and LCC substrate are $12.7 \times 12.7 \mathrm{~mm}$ and $13.7 \times 13.7 \mathrm{~mm}$ respectively. The substrate includes a recess $8.9 \times 8.9 \mathrm{~mm}$ by $1.27 \mathrm{~mm}$ deep. Figure 2 shows (a) the LCC substrate and (b) the Kovar ${ }^{\mathrm{TM}}$ lid (syringe-dispersed glass frit followed by organic burn-out and glazing with thickness around $250 \mu \mathrm{m}$ ) before bonding and (c) the bonded sample. In this case, to improve the laser beam absorption, a piece of silicon wafer of thickness $380 \mu \mathrm{m}$ was placed in good thermal contact with the KovarTM lid as shown in the figure, absorbing 69\% of the $940 \mathrm{~nm}$ laser light.
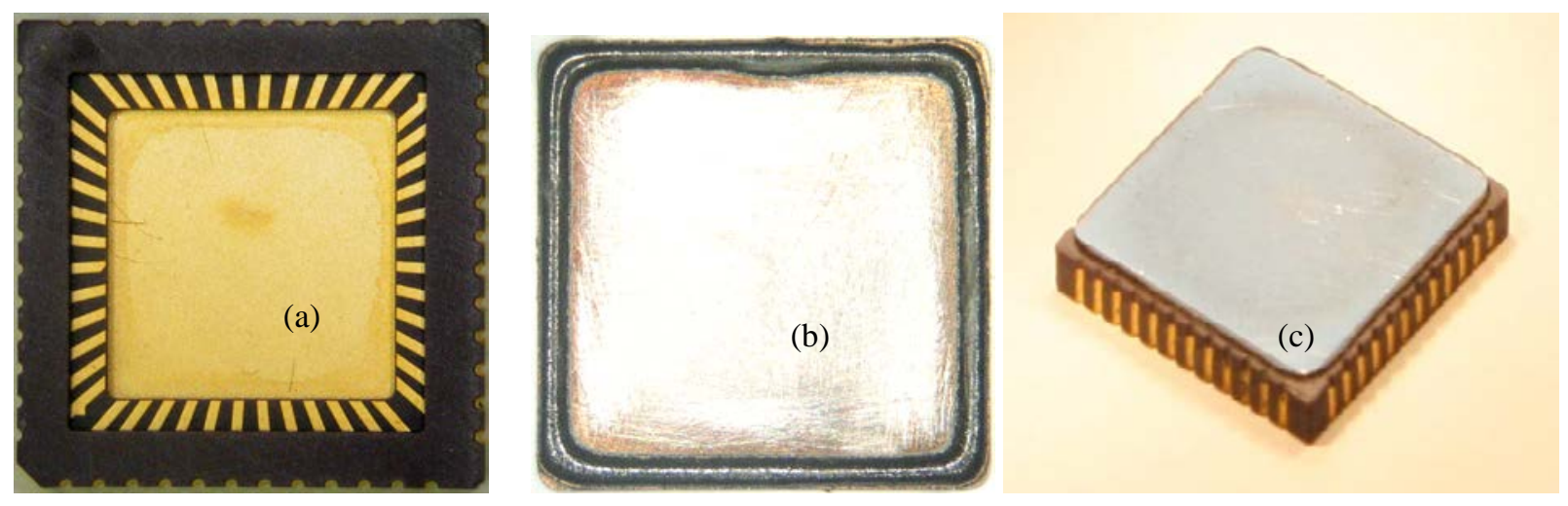

Figure 2 (a) LCC substrate and (b) Kovar ${ }^{\mathrm{TM}}$ lid (dispersed with glass frit) before bonding and (c) bonded sample

Fine and gross leak tests were carried out for the bonded samples, using a two-part process [1]; the gross leak test is essentially a pass/fail; whilst the fine leak test results are shown in table 1 . The acceptable leak rate, as defined by 
MIL-STD-883G, is $5 \times 10^{-8} \mathrm{mbar} \mathrm{l} \mathrm{s}^{-1}$ for a package of this volume. It is clear from the results presented in the table that a lower rate than this was achieved for a range of laser powers and bonding times.

Table 1 Fine leak test results of bonded LCC packages

\begin{tabular}{|c|c|c|c|}
\hline Laser Power (W) & Force (N) & Bonding time (s) & $\begin{array}{c}\text { Leak rate } \\
\left(\mathrm{mbar}^{-1} \text { ) }\right.\end{array}$ \\
\hline 35 & 2.25 & 140 & $1.3 \times 10^{-9}$ \\
\hline 40 & 1.96 & 100 & $1.1 \times 10^{-9}$ \\
\hline 60 & 1.96 & 40 & $2.2 \times 10^{-9}$ \\
\hline
\end{tabular}

Sectioning and polishing of the bonded sample were carried out to visually assess the joint quality across the bond. A typical micrograph of a sectioned sample is shown in figure 3, which indicates that glass frit has excellent contact with both the LCC substrate and $\operatorname{Kovar}^{\mathrm{TM}}$ lid, with no visible voids; it appears to have conformed well to the locally rough ceramic surface.

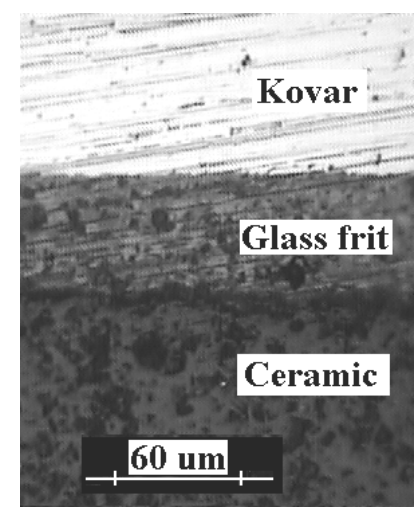

Figure 3 Micrograph of sectioned LCC package

\subsection{Laser bonding of Top-hat packages}

The "top-hat" cap consists of a raised square cap made of Kovar ${ }^{\mathrm{TM}}$, coated with a thin layer of nickel and then gold; however there was no coating at the bonding area - see figure 4(a) and (b). This cap is $9 \times 9 \mathrm{~mm}$, and $4 \mathrm{~mm}$ high. Two kinds of substrates were used in our experiments: AlN, $13 \times 13 \times 0.5 \mathrm{~mm}$ (figure $4(\mathrm{c})$ ), whilst the other is LTCC, $18 \times 18 \times 0.6 \mathrm{~mm}$ (figure 4(d)). The LTCC was plated with a $10 \mu \mathrm{m}$ thick Au track in the bonding region. 


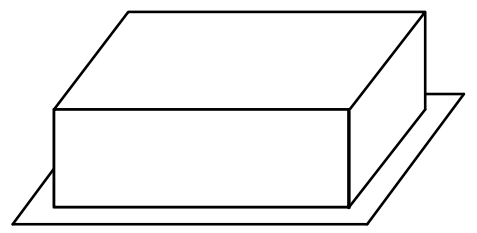

(a)

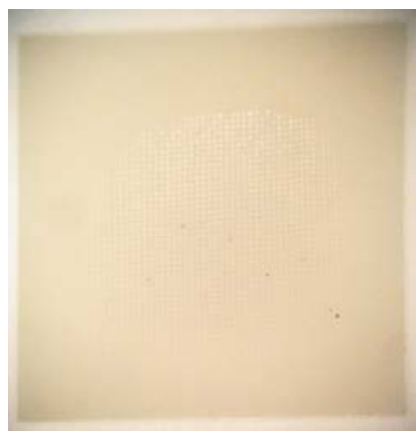

(c)

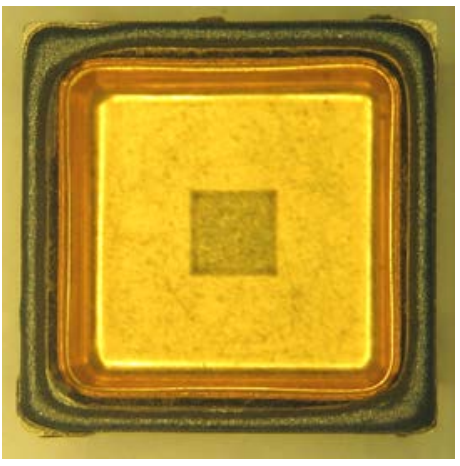

(b)

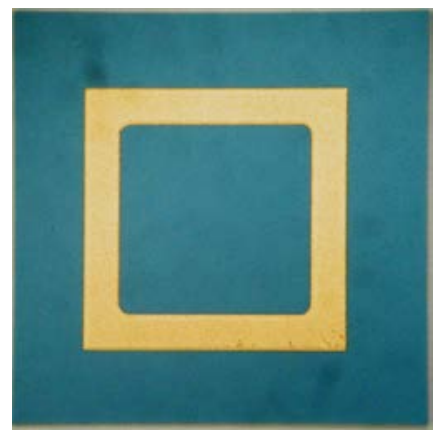

(d)

Figure 4 (a) Sketch of “top-hat” cap; (b) “top-hat” KovarTM cap dispersed with glass frit; (c) AlN and (d) LTCC substrate

In this case joining was carried out with the samples inverted; i.e. with the substrate uppermost. Examples of the bonded samples are shown in figure 5 .

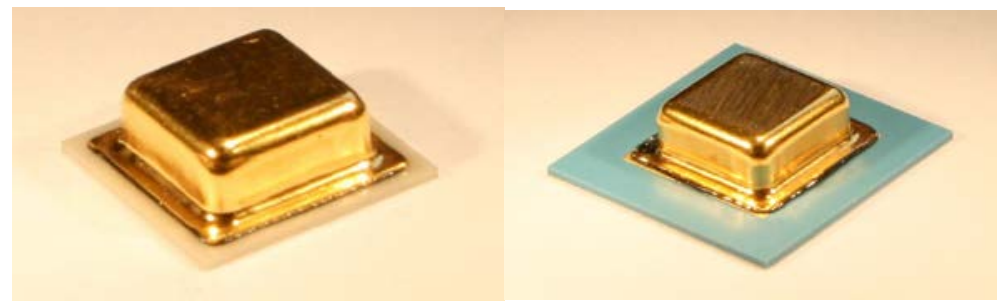

(a)

(b)

Figure 5 Laser bonded sample of (a) AlN and (b) LTCC substrate to top-hat cap

Successful bonding was achieved, although a higher power laser power of $\sim 100 \mathrm{~W}$ was required for LTCC, in comparison with 40 - $50 \mathrm{~W}$ with AlN. These bonded samples all passed the gross leak test, and met the MIL-STD 883G criteria in the fine leak test (again $5 \times 10^{-8} \mathrm{mbar} \mathrm{l} \mathrm{s}^{-1}$, given the $0.26 \mathrm{~cm}^{3}$ internal volume). Detailed results are shown in tables 2 and 3 below. The bonding force used in each case was $1.96 \mathrm{~N}$. 
Table 2 Fine leak test results of AlN substrate bonded to top-hat KovarTM cap

\begin{tabular}{|c|c|c|}
\hline Laser Power (W) & Bonding time (s) & $\begin{array}{c}\text { Leak rate } \\
\left(\mathrm{mbar} \mathrm{l} \mathrm{s}^{-1}\right)\end{array}$ \\
\hline 40 & 40 & $4.8 \times 10^{-9}$ \\
\hline 45 & 30 & $1.1 \times 10^{-9}$ \\
\hline 50 & 26 & $1.3 \times 10^{-9}$ \\
\hline
\end{tabular}

Table 3 Fine leak test results of LTCC substrate bonded to top-hat Kovar ${ }^{\mathrm{TM}}$ cap

\begin{tabular}{|c|c|c|}
\hline Laser Power (W) & Bonding time (s) & $\begin{array}{c}\text { Leak rate } \\
\left(\mathrm{mbar} \mathrm{l} \mathrm{s}^{-1}\right)\end{array}$ \\
\hline 100 & 80 & $1.4 \times 10^{-9}$ \\
\hline 120 & 50 & $1.7 \times 10^{-9}$ \\
\hline
\end{tabular}

To visually assess the bonded joint, samples were sectioned and polished. Example micrographs are shown in figure 6. Again, the glass frit makes excellent contact with both these samples, conforming well to the joined surfaces.

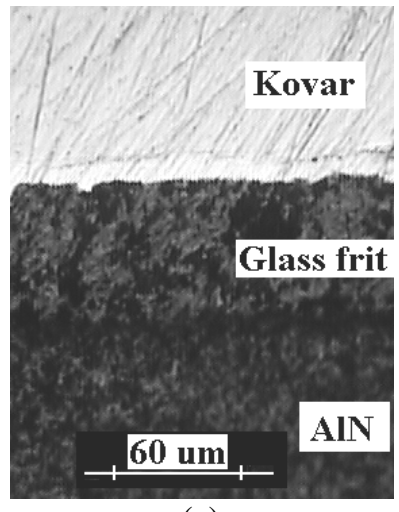

(a)

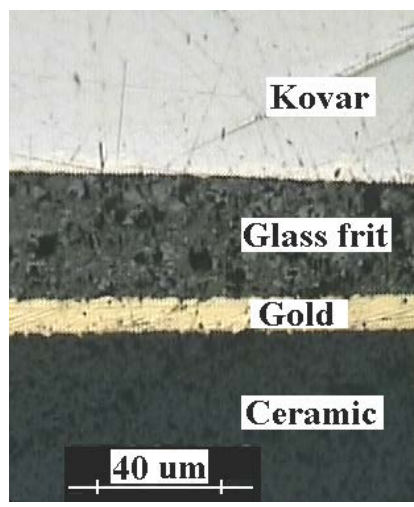

(b)

Figure 6 Micrograph of section (a) AlN and (b) LTCC substrate to top-hat Kovar'TM cap

\section{Influence of micro-machined channels/slots on hermeticity and shear force}

Bonding surface roughness is an important issue in most hermetic packaging technology. Many processes require very flat surfaces to be used; however the results presented above demonstrate that the glass frit has the ability to conform well to naturally rough surfaces. In this section we report on our more detailed investigation of the impact of non-planar joining surfaces on hermeticity and shear strengths; specifically surfaces containing micro-machined channels / slots. 
In this section we introduce our final sample, which has a silicon substrate, in addition to the LTCC and AlN substrates used in the experiments described earlier. Each substrate was modified by laser machining a series of closely-spaced slots into the surface. The slot depth generated was slightly different in each case, as shown in the micrographs of sectioned samples in figure 7; meanwhile the SEM images shown in figure 8 provide an indication of the extent the surface roughness in each case. The slot depths are shown more clearly in the micrographs shown in figure 8.

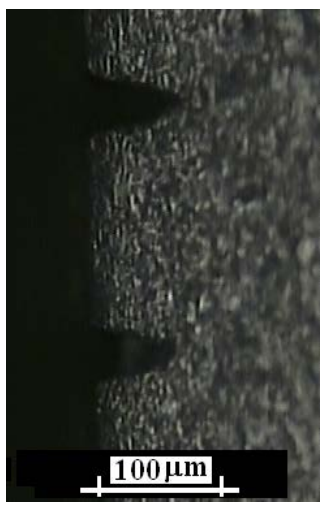

(a)

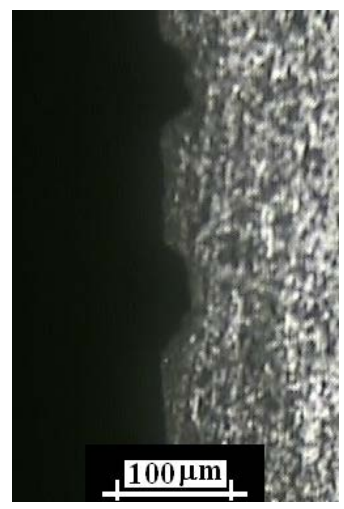

(b)

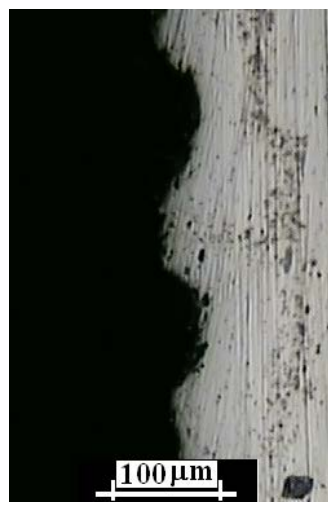

(c)

Figure 7 Micrographs of the cross-section of laser machined (a) LCC (b) AIN and (c) silicon substrate

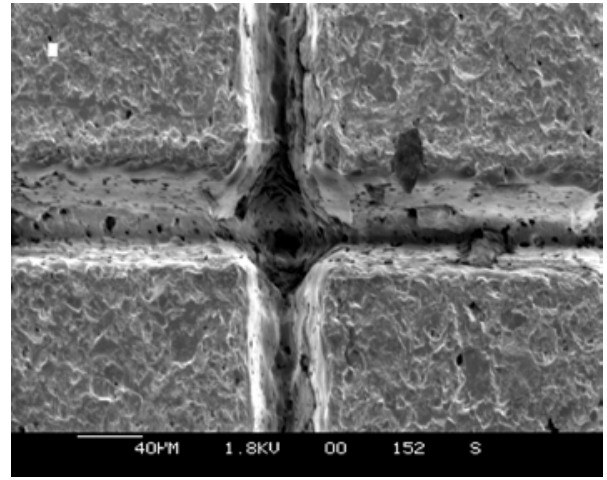

(a)

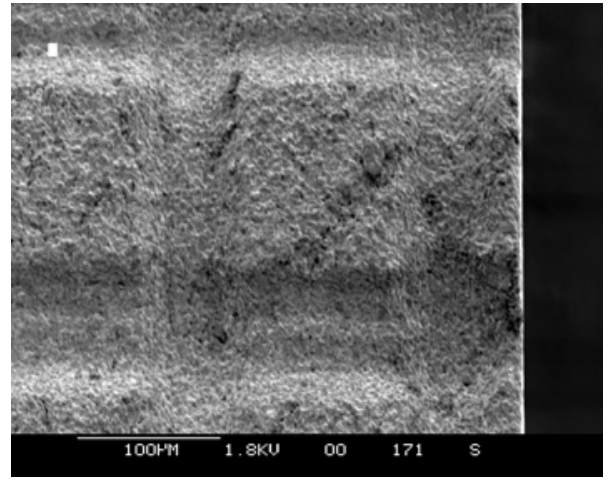

(b)

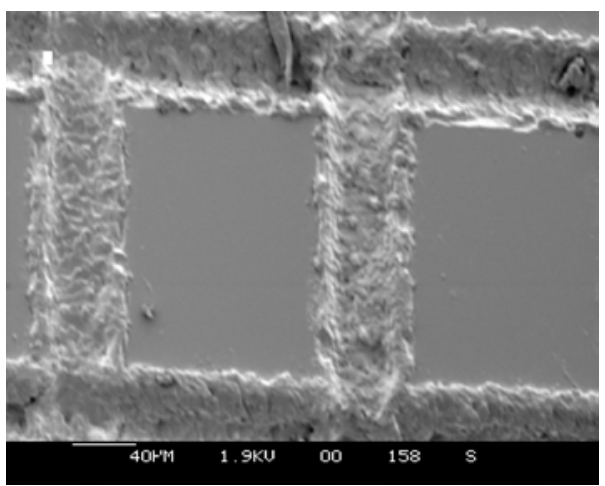

(c) 
Figure 8 SEM images of the surface roughness of laser machined substrates (a) LCC (b) AlN and (c) silicon, providing an indication of surface roughness, both of the original sample and in the laser-machined region

Of interest here is not only the leak rate that can be achieved, but also the shear strength. First of all, non-machined samples were tested. The LCC packages had a shear strength of $62 \mathrm{~kg}$, whilst both the AlN and silicon were only $\sim 5 \mathrm{~kg}$. With the laser-machined samples, leak rates of less than $5 \times 10^{-8} \mathrm{mbar} \mathrm{s} \mathrm{s}^{-1}$ were consistently achieved, demonstrating the excellent ability of the glass frit to conform to the joining surfaces. The laser machining did, however, influence the shear strength for both the AlN and silicon substrates; in both cases it was increased to $\sim 10 \mathrm{~kg}$ provided that the grooves were at least 20 - $30 \mu \mathrm{m}$ deep. With the LCC substrate, no such increase was observed; however it is clear from figure 8 that the unprocessed surface in this case already has a significant roughness in comparison with the other samples. It is hence clear that one potential drawback of glass frit is a relative lack of strength when joining very smooth surfaces; however in general it is easier to produce a sample with rough surface than a smooth one.

To visually assess the joint line of bonded area, sectioning and polishing of the bonded samples were carried out. Micrographs of the sectioned samples are shown in figure 9; here it is clear that the glass frit has flowed into the laser-machined slot, providing excellent contact in all cases.

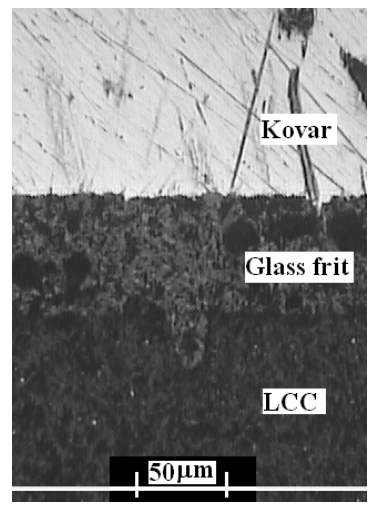

(a)

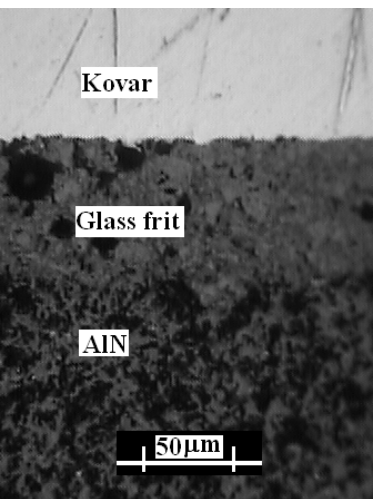

(b)

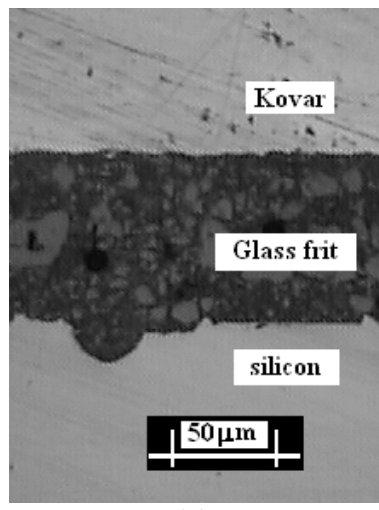

(c)

Figure 9 Micrographs of sectioned packages, (a) LCC with a $\operatorname{Kovar}^{\mathrm{TM}}$ lid; (b) AlN with Kovar $^{\mathrm{TM}}$ "top-hat” cap and (c) silicon with $\mathrm{Kovar}^{\mathrm{TM}}$ "top-hat" cap

\section{Laser based localised bonding technique}

In the investigations detailed above, we were not concerned about preventing heating inside the joined packages; indeed for simplicity the samples to be joined are placed on top of a glass slide. However this will heat the whole 
sample to a high temperature due to the lateral heat transfer, in particular with the silicon substrate, which has a high thermal conductance. To prevent lateral heating of the centre of the substrate, it is necessary to place a cooled thermally conductive block (in our case copper was used) in contact with the underside of the substrate, to act as a heat sink [24]. To prevent excessive heat loss, and hence reduce the requirement for average laser power, this heat sink was designed to be only in contact with the centre of the package, to cool any temperature-sensitive elements inside, as shown in figure 10.

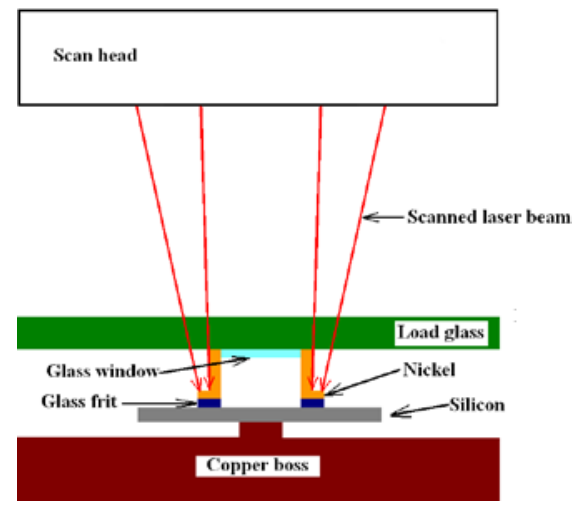

Figure 10 schematic of localised laser bonding with copper boss cooling unit

To test this cooling technique, we investigated the bonding of a TO5 Nickel cap to silicon; this particular sample was chosen as in this case truly localised heating is particularly difficult to achieve, given the high thermal conductivity of the silicon substrate. It is important to ensure a uniform temperature throughout the glass frit, to ensure that it is fully cured. As a result the approach adopted for laser heating was to scan the focused laser spot on the silicon substrate, just outside the Ni cap, in a ring of diameter $10.4 \mathrm{~mm}$ and width $0.35 \mathrm{~mm}$.

\subsection{Finite element simulation}

In addition to the experiments, a finite element simulation was constructed in FlexPDE to determine the temperature field likely to be generated in this case. The simulation is based on the heat equation in an isotropic and homogeneous medium:

$\frac{\partial u}{\partial t}=\frac{\kappa}{c \rho}\left(\frac{\partial^{2} u}{\partial^{2} x}+\frac{\partial^{2} u}{\partial^{2} y}+\frac{\partial^{2} u}{\partial^{2} z}\right)$

where $u=u(t, x, y, z)$ is temperature which is a function of both time and space; $\kappa$ is the thermal conductivity; $c$ is the specific heat, and $\rho$ the density.

We assumed that the laser heat source has a Gaussian Irradiance profile 
$I(r)=\frac{2 P}{\pi \omega^{2}}(1-R) \exp \left(-\frac{2 r^{2}}{\omega^{2}}\right)$

Where $P$ is the laser output power, $R$ is the reflectivity of material, $\omega$ is the radius of the laser beam.

This model was constructed for the setup shown in figure 10 and the laser energy was assumed to be absorbed at the surface of the silicon (of thickness $380 \mu \mathrm{m}$ and reflectivity of 31\%). The temperature at the bottom surface of the copper is fixed at $300 \mathrm{~K}$ (water cooled), and the temperature at the top layer of glass is also assumed as $300 \mathrm{~K}$ and the heat transfer coefficient of ambient air is $40 \mathrm{~W} \mathrm{~m}^{-2} \mathrm{~K}^{-1}$ [25]. Radiative heat transfer was also included between the closely spaced surfaces in the device and into the surrounding air. To simplify the simulation process, we assume first of all that the temperature has reached a steady state and the laser illumination on the silicon surface is continuous because of its very high scanning speed $(1000 \mathrm{~mm} / \mathrm{s})$, forming a ring of diameter $10.4 \mathrm{~mm}$ and width $0.35 \mathrm{~mm}$. However, a time-dependant simulation was also carried out to investigate the evolution of temperature with time. Results from this model are presented in figure 11(c), for 3 points on the silicon surface, namely in the centre of the silicon chip, within the glass frit ring and directly below the laser illumination track.

We also assume an imperfect thermal contact between the copper boss and silicon, as they are not completely flat, but each have a certain surface roughness; to model this we treat it as a $3 \mu \mathrm{m}$ air gap. The outer diameter of the TO5 cap is $8.3 \mathrm{~mm}$ and it has a 'lip' of width $0.5 \mathrm{~mm}$ at the base, whilst the substrate is $12 \times 12 \mathrm{~mm}$, i.e. the laser illuminates a ring on the substrate slightly larger than the TO5 cap. Figure 11(a-b) shows the calculated temperature field arising from 61 W laser illumination.

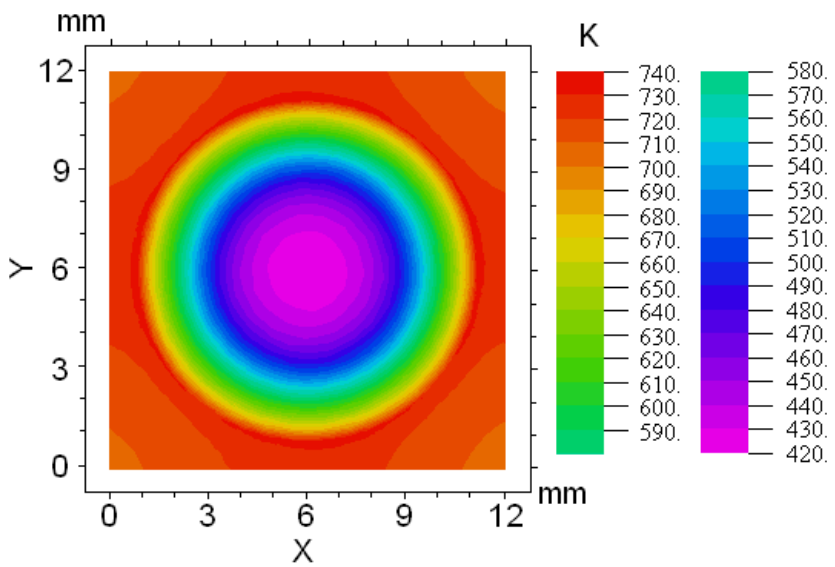

(a) 


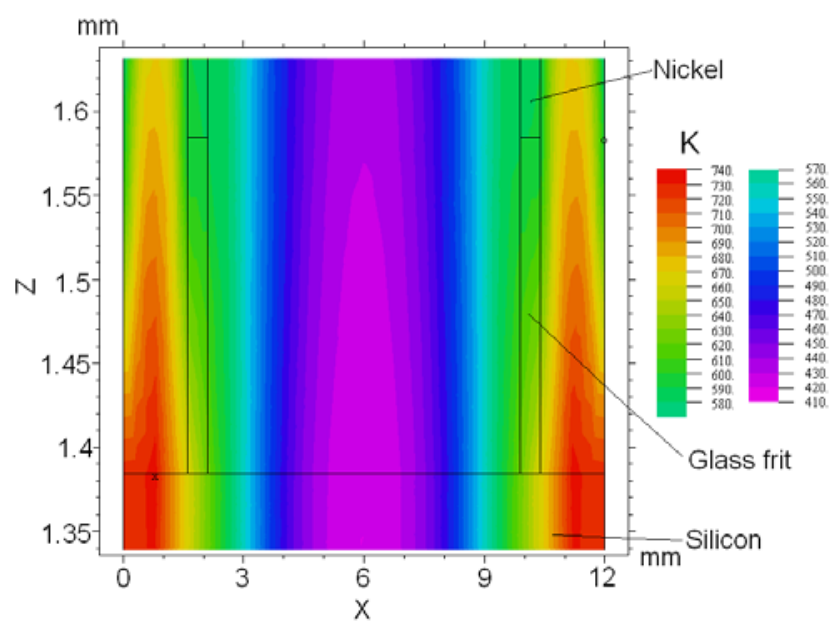

(b)

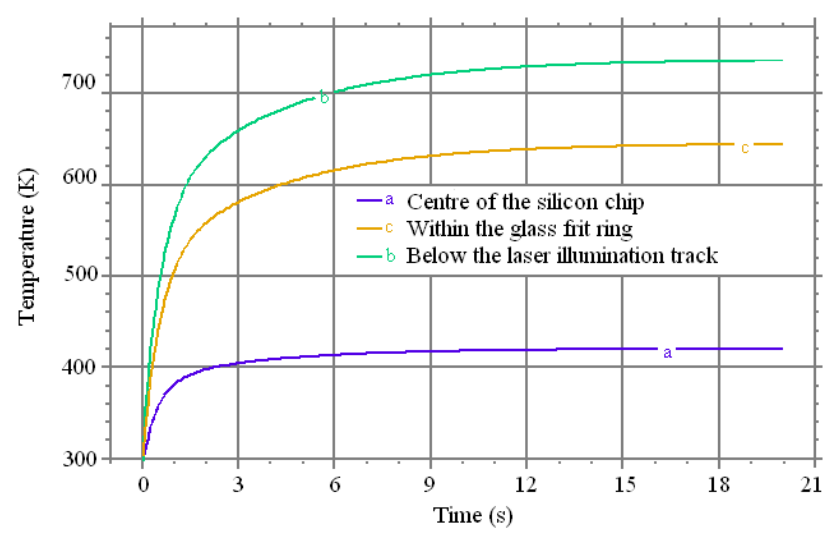

(c)

Figure 11 Calculated temperature field (a) at the silicon substrate surface and (b) at a cross-section through the centre of the top-hat (at $y=6 \mathrm{~mm}$ ); (the z-axis is magnified in the figure); and (c) the temporal evolution of temperature at 3 points on the silicon surface, namely in the centre of the silicon chip, within the glass frit ring and directly below the laser illumination track.

It can be seen in figure 11(a) that the temperature distribution expected within the glass frit ring is reasonably uniform. The calculated temperatures at the outer and inner edges of the glass frit ring at the silicon surface are $664 \mathrm{~K}$ and 626 K respectively, a difference of $38 \mathrm{~K}$. Furthermore, figure 11(b) shows that the predicted temperatures on the bottom and top of the glass frit at ring centre are $644 \mathrm{~K}$ and $590 \mathrm{~K}$ respectively, i.e. a difference of $54 \mathrm{~K}$. Meanwhile, the temperature at the centre of the silicon substrate should be kept to around $420 \mathrm{~K}$, so the heating is properly localised. 
It can be seen from figure 11(c) that after $10 \mathrm{~s}$ laser illumination, the temperatures in the centre of the silicon chip, within the glass frit ring and directly below the laser illumination track are 724, 634 and $418 \mathrm{~K}$ respectively; in each case this is at least $97 \%$ of the temperature at steady state. This indicates that the steady state model is appropriate for the laser scanning times used here.

It is noted that it is important to include the effect of radiative heat transfer in the model; if this is omitted, the simulated maximum temperature obtained with a reduced laser power of $58 \mathrm{~W}$ is the same as that with a laser power $61 \mathrm{~W}$ when radiation is included.

\subsection{Experimental - scanning beam}

A series of experiments were carried out; however there was found to be a problem on the cooling phase. A few seconds after completing the laser heating phase, a ‘cracking' noise could always be heard. On inspection it was clear that a thermally-induced crack was occurring in the glass frit. Such a crack is likely to arise from different cooling rates in the silicon and glass frit, due to the high thermal conductivity of both the silicon substrate and Cu support/heat sink. It was found that reducing the laser power in a stepwise fashion, and adding a cooling gas flow to the cap towards the end of the heating process, could reduce the likelihood of this cracking, but not completely eliminate it.

An additional refinement was therefore made to the experimental arrangement, whereby the Cu support was moved away from the silicon substrate immediately after the laser shutter was closed, i.e. at the end of the heating cycle, whilst the cooling gas flow was maintained for a further $15 \mathrm{~s}$. After optimisation of the bonding parameters, a series of 6 samples was bonded, and an improved success rate of $66 \%$ (4 out of 6) was obtained. Parameters used were: laser

power of $55 \mathrm{~W}$ for $150 \mathrm{~s}$, followed by $46 \mathrm{~W}$ for $10 \mathrm{~s}$, and the cooling gas flow started at $135 \mathrm{~s}$. Provided no cracking occurred, the leak rate was always less than $2.0 \times 10^{-9} \mathrm{mbar} \mathrm{l} \mathrm{s}^{-1}$. The laser was scanned over a ring of diameter $10.4 \mathrm{~mm}$, on a $12 \times 12 \mathrm{~mm}$ silicon substrate.

To determine the maximum temperature reached in the centre of the silicon sample, further experiments were carried out by coating the centre of the silicon with a temperature indicating paint (Tempilaq, Tempil Inc). With an illumination laser power of $56 \mathrm{~W}$ for 150 seconds, this paint demonstrates that the temperature in the centre of the 
silicon was in the range 505 to $526 \mathrm{~K}$, higher than indicated from the simulation (most likely due to poor thermal contact between the silicon and the copper), but still significantly below the glass frit curing temperature of around $640 \mathrm{~K}$.

\subsection{Experimental - focused ring}

An axicon is a cone-shaped optic, and in combination with a positive lens can create a 'ring focus'. Figure 12 shows a cross-section through an axicon-lens arrangement, demonstrating this effect, given the circular symmetry of the axicon.

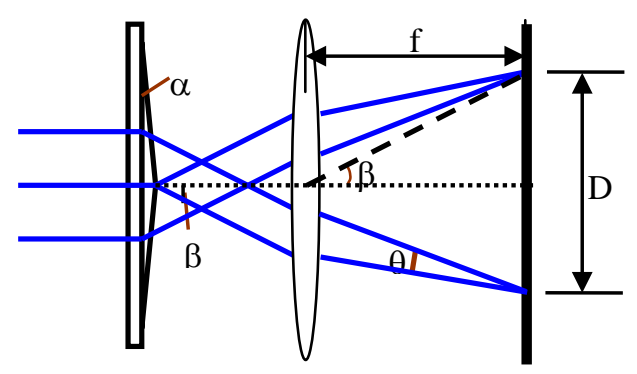

Figure 12 Schematic figure of an axicon ring

In our setup, fibre-delivered light is collimated with a $+100 \mathrm{~mm}$ focal length lens before passing through the axicon followed by a positive focal length focusing lens, generating a focused laser ring of diameter 12 mm and width 1 mm. The silicon substrate in this case was $14 \times 14 \mathrm{~mm}$, and as with the scanning system, the Ni cap is not heated directly, but rather the silicon substrate immediately surrounding the cap. As with the laser scanning technique, a cooling gas flow was used towards the end of the heating phase, and the silicon separated from the Cu cooling block at the end of the heating phase. An illumination laser power in the range of 60 to $68 \mathrm{~W}$ was used for $100 \mathrm{~s}$, and then reduced to $45 \mathrm{~W}$ for $10 \mathrm{~s}$. A cooling gas flow was started $85 \mathrm{~s}$ after the start of the heating phase. In all cases, the parts were successfully joined (20 parts), with a leak rate of $1.7 \times 10^{-9} \mathrm{mbar} \mathrm{l} \mathrm{s}^{-1}$ or less. Measurements with Tempilaq paint demonstrate that the maximum temperature was in the range 505 to $526 \mathrm{~K}$.

\section{Conclusions and discussions}

Knechtel [20] states that the advantages of glass frit bonding are high bonding strength and process yield, low stress at the bonding interface, good process repeatability, hermetic sealing and non-stringent requirements for the flatness of 
the surfaces to be bonded. The laser-based process investigated in this paper combines these advantages with localised heating and a high speed process.

In this paper, we have demonstrated the versatility of laser-based bonding using glass frit for a range of miniature packages and materials, where hermetic seals are required. We have demonstrated that the process is highly suited to rough or non-flat surfaces; indeed with a smooth surface it is beneficial to machine micro-slots into the surface before joining. Care must however be taken when using localised heating to join materials of differing thermal parameters; differential cooling can lead to stress across the join and hence failure by cracking of the glass frit. A potential solution has been demonstrated in this paper for a particular sample configuration.

\section{Acknowledgments}

The authors acknowledge the financial support of the Engineering and Physical Sciences Research Council in the UK.

The authors are also grateful to Steve Riches (GE Aviation Systems), John Betterton (QinetiQ), John Gillham (QinetiQ) for fruitful discussions and provision of samples.

\section{References}

\section{[1] http://www.intertest.cc/seal_test.html}

[2] L. Lin, Y. T. Cheng, and K. Najafi, "Formation of silicon-gold eutectic bond using localized heating method," Jpn. J. Appl. Phys. 2, Lett., vol. 37, no. 11B, pp. 1412-1414, Nov. 1998.

[3] Y. T. Cheng, W. T. Hsu, K. Najafi, C. T. C. Nguyen, and L. Lin, "Vacuum packaging technology using localized aluminum/silicon-to-glass bonding,” J. Microelectromech. Syst., vol. 11, no. 5, pp. 556-565, Oct. 2002.

[4] Y. T. Cheng, L. Lin, and K. Najafi, "Localized silicon fusion and eutectic bonding for MEMS fabrication and packaging,” J. Microelectromech. Syst., vol. 9, no. 1, pp. 3-8, 2000.

[5] R. J. K. Wassink, Soldering in Electronics. Ayr, U.K.: Electrochemical Publications, 1984.

[6] H. Noh, K. Moon, A. Cannon, P. J. Hesketh, and C. P. Wong, "Wafer bonding using microwave heating of parylene for MEMS packaging,” in Proc. IEEE Int. Conf. Electron. Compon. and Technol., 2004, vol. 1, pp. 924-930.

[7] H. A. Yang, M. Wu, and W. Fang, "Localized induction heating solder bonding for wafer level MEMS packaging,” in Proc. IEEE Int. Conf. Micro Electro Mech. Syst., 2004, pp. 729-732.

[8] Chen, M. X.; Yuan, L. L.; Liu, S. (2007) Research on low-temperature anodic bonding using induction heating. Sensors and Actuators A-Physical 133, 266-269

[9] C. Barbatti, J. Garcia, G. Liedl, A. Pyzalla, “Joining of cemented carbides to steel by laser beam welding”, MATERIALWISSENSCHAFT UND WERKSTOFFTECHNIK 38 (11): 907-914 NOV 2007 
[10] Xiujing Liu, “Joining dissimilar metal magnesium and aluminum by laser”, RARE METALS 26: 175-179 Sp. Iss. SI, AUG 2007

[11]W. Watanabe, S. Onda, T. Tamaki, K. Itoh, "Direct joining of glass substrates by $1 \mathrm{kHz}$ femtosecond laser pulses”, APPLIED PHYSICS B-LASERS AND OPTICS 87 (1): 85-89 MAR 2007

[12] A.W.Y. Tan, F.E.H. Tay, "Localized laser assisted eutectic bonding of quartz and silicon by Nd : YAG pulsed-laser”, SENSORS AND ACTUATORS A-PHYSICAL 120 (2): 550-561 MAY 172005

[13] Alexandre Mathieu, Rajashekar Shabadi, Alexis Deschamps, Michel Suery, Simone Mattei, Dominique Grevey, Eugen Cicala, "Dissimilar material joining using laser (aluminum to steel using zinc-based filler wire)", OPTICS AND LASER TECHNOLOGY 39 (3): 652-661 APR 2007

[14] U. M. Mescheder, M. Alavi, K. Hiltmann, C. Lietzau, C. Nachtigall, and H. Sandmaier, "Local laser bonding for low temperature budget,” Sens. Actuators A, Phys., vol. 97/98, pp. 422-427, 2002.

[15] C. Luo and L. Lin, "The application of nanosecond-pulsed laser welding technology in MEMS packaging with a shadow mask,” Sens. Actuators A, Phys., vol. 97/98, pp. 398-404, 2002.

[16] A. Nishimoto, M. Ando, M. Takahashi, M. Aritoshi, K. Akamatsu, K. Ikeuchi, "Interfacial microstructure of $\mathrm{SiC} / \mathrm{Cu}$ joint friction-bonded with $\mathrm{Ti}$ intermediate layer", JOURNAL OF THE JAPAN INSTITUTE OF METALS 67 (10): 538-546 OCT 2003

[17] F. Bardin, S. Kloss, C. Wang, A.J. Moore, A. Jourdain, I.D. Wolf, D.P. Hand, "Laser bonding of glass to silicon using polymer for Microsystems packaging”, Journal of Microelectromechanical systems, vol. 16 (3): 571-580, 2007

[18] C. Dresbach, A. Krombholz, M. Ebert, J. Bagdahn, "Mechanical properties of glass frit bonded micro packages“, MICROSYSTEM TECHNOLOGIES-MICRO-AND NANOSYSTEMS-INFORMATION STORAGE AND PROCESSING SYSTEMS 12 (5): 473-480 MAR 2006

[19] R. Knechtel, M. Wiemer, J. Fromel, "Wafer level encapsulation of microsystems using glass frit bonding“, MICROSYSTEM TECHNOLOGIES-MICRO-AND NANOSYSTEMS-INFORMATION STORAGE AND PROCESSING SYSTEMS 12 (5): 468-472 MAR 2006

[20]R. Knechtel, "Glass frit bonding: an universal technology for wafer level encapsulation and packaging”, MICROSYSTEM TECHNOLOGIES-MICRO-AND NANOSYSTEMS-INFORMATION STORAGE AND PROCESSING SYSTEMS 12 (1-2): 63-68 DEC 2005

[21]D. Sparks, S. Massoud-Ansari, N. Najafi, "Long-term evaluation of hermetically glass frit sealed silicon to Pyrex wafers with feedthroughs”, JOURNAL OF MICROMECHANICS AND MICROENGINEERING 15 (8): 1560-1564 AUG 2005

[22]Z. Sun, D. Pan, J. Wei, C.K. Wong, “Ceramics bonding using solder glass frit”, JOURNAL OF ELECTRONIC MATERIALS 33 (12): 1516-1523 DEC 2004

[23] http://www.diemat.com/docs/products/glass/pdf/DM2700P-H848\%202008-03-18.pdf

[24] Q. Wu, N. Lorenz, and D.P. Hand, "Localised laser joining of glass to silicon with BCB intermediate layer”, Microsystem Technologies-micro-and nanosystems-information storage and processing systems, vol. 15, no. 7, pp. 1051-1057, 2009

[25] http://www.cheresources.com/insulationzz.shtml 


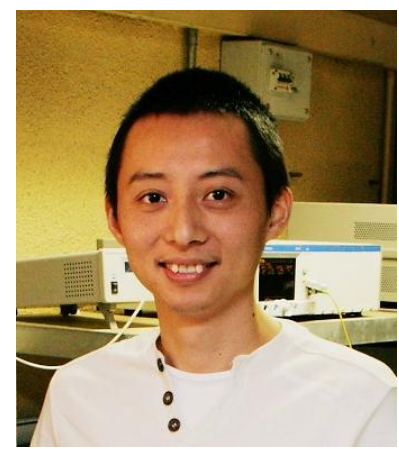

Qiang Wu received his B.S. degree from Beijing Normal University, China, in 1996 and a Ph.D degree from Beijing University of Posts and Telecommunications, China, in 2004.

From 1996 to 1999, he worked as an Assistant Lecturer in theoretical physics at Jiangxi Normal University, China. In 2004, he worked as a Senior Research Associate in the Optoelectronics Research Centre, City University of Hong Kong, carrying out research into polymer optical waveguides. From 2006 to 2008, he was a Research Associate in the Applied Optics and Photonics Group at Heriot-Watt University in Edinburgh in Scotland, research aspects of laser jointing in micro-manufacture.

Dr. Wu joined the Dublin Institute of Technology (DIT) in August 2008 as an SFI funded "Stokes Lecturer" at the School of Electronic and Communications Engineering. He is now working within the Photonics Research Group at DIT on aspects of fast optical wavelength measurement, fibre optic sensing and multi-channel fibre Bragg gratings.

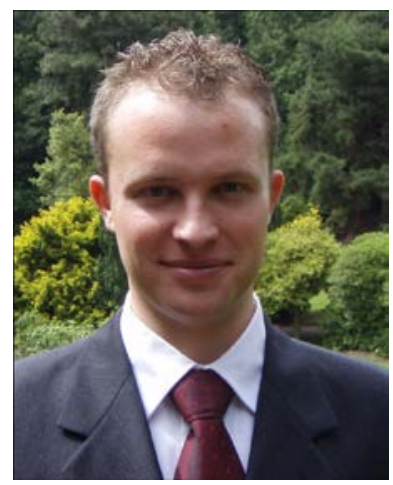

Norbert Lorenz received a Diplom Ingenieur (FH) in Photonics from the University of Applied Science Emden, Germany in 2007. For the corresponding thesis he worked at the Forschungszentrum Karlsruhe, Germany, where his research aimed at the production of waveguides structures in PMMA using excimer lasers in direct writing processes. He is studying towards a $\mathrm{PhD}$ on the subject "Laser-joining in Microsystems" at Heriot-Watt University in Edinburgh, UK. His research concentrates on the development of new laser-based MEMS and micro-devices encapsulation processes using localised heating.

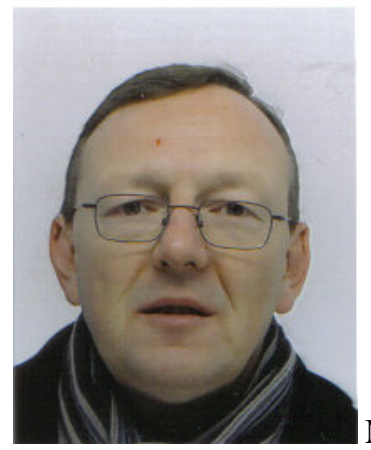

Mr K M Cannon, Bishops Stortford, Hertfordshire 1961 received a BEng degree in Electrical and Electronic Engineering from the University of Brighton, UK, in 1987.

He moved to GE Aviation, Tewkesbury (formerly Smiths Aerospace) as a Manufacturing Process Engineer in 1988 to 
develop the interconnection and packaging technologies for Multi-Chip-Modules devices and participated in the RISH and MCMC funded programs.

In 2008 he was promoted to the position of Operations Manager for the site were his current interest are in the packaging of Micro System devices which includes MEM's and Sensors technologies.

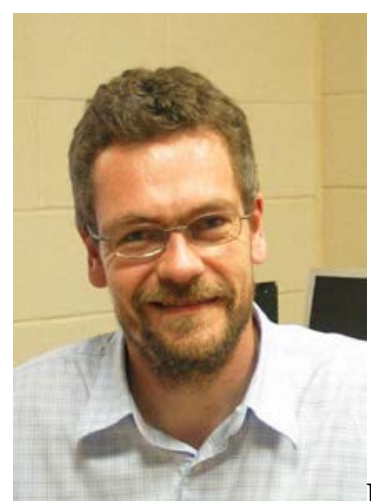

Prof Duncan Hand received a BSc degree in physics with electronics in 1986 from the University of St Andrews, UK, and a PhD entitled 'periodic structures in optical fibres' from the University of Southampton, UK, in 1991.

He moved to Heriot-Watt University in 1991, to work as a Research Associate. In 1997 he obtained a Lectureship position at the same institution, was promoted to Reader in 2001 and Professor of Applied Photonics in 2003. His current research interests encompass a wide range of applications of high power lasers, primarily in manufacturing processes (laser precision machining; laser joining) and in medicine (surgery; dentistry). This work includes research into the delivery of the high peak power laser light via novel optical fibres and other optics.

Prof. Hand is a Fellow of the Institute of Physics, and Consultant Professor of Beijing University of Posts and Telecommunications. 